\title{
ETNOGRAFIA VIRTUAL EM ALCOÓLICOS ANÔNIMOS EM TEMPOS DE PANDEMIA
}

\section{VIRTUAL ETHNOGRAPHY IN ALCOHOLICS ANONYMOUS IN TIMES OF PANDEMIC}

\author{
Edemilson Antunes de Campos ${ }^{1}$
}

\begin{abstract}
Resumo: O objetivo deste artigo é compreender como os membros de Alcoólicos Anônimos (A.A.) realizam o tratamento do alcoolismo em meio à pandemia, por meio de uma etnografia virtual em grupos de A.A. no Brasil. Com a pandemia, os membros de AA desclocaram suas reuniões de recuperação para o espaço virtual, obrigando-os a enfrentarem os desafios de realizarem o tratamento do alcoolismo por meio de reuniões on-line. A pesquisa acadêmica também teve que se reinventar de modo que a etnografia, método clássico da pesquisa antropológica, também migrou para o espaço virtual, o que tem provocado certos tensionamentos em relação à clássica noção de trabalho de campo em antropologia. Busca-se, assim, contribuir para a compreensão da maneira como os membros de A.A. realizam o tratamento do alcoolismo em reuniões de recuperação online e, por essa via, dos desafios teóricos e metodológicos da etnografia virtual em tempos de pandemia.
\end{abstract}

Palavras-chave: Alcoolismo; Alcoólicos Anônimos; Etnografia Virtual; Pandemia.

\begin{abstract}
The aim of this article is to understand how the members of Alcoholics Anonymous (A.A.) carry out the treatment of alcoholism in the midst of the pandemic, through a virtual ethnography in A.A. groups in Brazil. In the pandemic, AA members moved their recovery meetings to the virtual space, forcing them to face the challenges of taking alcoholism treatment through online meetings. Academic research also had to reinvent itself so that ethnography, the classic method of anthropological research, also migrated to virtual space, which has caused certain tensions in relation to the classical notion of fieldwork in anthropology. The aim is, therefore, to contribute to the understanding of the way A.A. members carry out the treatment of alcoholism in online recovery meetings and, in this way, the theoretical and methodological challenges of virtual ethnography in times of pandemic.
\end{abstract}

Keywords: Alcoholism; Alcoholics Anonymous; Virtual Ethnography; Pandemic.

\section{Introdução}

A pandemia causada pelo novo Coronavírus transformou o cenário mundial desde o dia 31 de dezembro de 2019, a data em que a Organização Mundial de Saúde (OMS) foi alertada sobre vários casos de pneumonia na cidade de Wuhan, na República Popular da China. A causa da pneumonia foi descoberta uma semana depois no dia 7 de janeiro de 2020 pelas autoridades chinesas, como sendo um novo tipo de Coronavírus não antes identificado em seres humanos. Esse novo Coronavírus, chamado SARS-Cov-2 é o responsável por causar a doença Covid-19.

\footnotetext{
${ }^{1}$ Livre-Docente pela Universidade de São Paulo (USP), Escola de Artes, Ciências e Humanidades, Universidade de São Paulo (EACH-USP), São Paulo, São Paulo, Brasil. E-mail: edicampos@usp.br
} 
No Brasil, em janeiro de 2020, o Centro de Operações de Emergências em Saúde Pública para o novo Coronavírus foi ativado como estratégia prevista no Plano Nacional de Resposta às Emergências em Saúde Pública, do Ministério da Saúde, para recomendações e atuação frente à diminuição do contágio e mortes em decorrência da Covid-19. Em março de 2020, a OMS declarou a Covid-19 como pandemia, devido sua distribuição geográfica, reconhecendo que existiam surtos de Covid-19 em vários países e regiões do mundo. Apesar disso, o Brasil não conseguiu controlar a transmissão da doença e a OMS declarou que a América do Sul era o novo epicentro da doença e que o Brasil era o país mais afetado, fato que permanece até os dias atuais.

Como forma de tentar conter a propagação do vírus, as autoridades sanitárias da OMS e de diversos países implementaram medidas de distanciamento social, para se evitar aglomerações de pessoas, o uso de máscaras e a higienização frequente das mãos.

A pandemia da Covid-19 alterou nosso modo de vida, obrigando a uma reorganização da vida social e econômica, com impacto também na pesquisa acadêmica, que teve que se adaptar a essa nova realidade, com uma revisão de seus métodos e técnicas de pesquisa. Exemplo disso é a etnografia, método clássico da pesquisa antropológica, que se baseia no contato face a face entre pesquisador e pesquisado com o objetivo de se compreender uma determinada realidade sociocultural. Na pandemia, os pesquisadores foram obrigados a repensar a realização da pesquisa etnográfica, adaptando-a ao contexto virtual.

Todavia, a chamada etnografia virtual nos leva a pensar os desafios teóricos e metodológicos em relação à clássica noção de trabalho de campo em antropologia e as interações entre pesquisadores e pesquisados, bem como o emprego de técnicas de coleta de dados próprias da produção de conhecimento antropológico, como a observação participante e as diversas modalidades de entrevistas e, por fim, as estratégias de análise do material empírico.

Nesse artigo, busca-se compreender como os membros de A.A. realizam o tratamento do alcoolismo em meio à pandemia, por meio de uma etnografia virtual em grupos de A.A. no Brasil. Trata-se de compreender tratamento do alcoolismo em A.A. e os desafios teóricos e metodológicos da etnografia virtual em tempos de pandemia. 


\section{A etnogrofia virtual: desafios teóricos e metodológicos}

O método etnográfico de pesquisa constitui um conjunto de concepções e procedimentos utilizados, tradicionalmente, pela Antropologia, com o objetivo de compreender cientificamente uma dada realidade sociocultural. Desde os estudos clássicos de Malinowiski (1986), fazer antropologia se confunde com a prática da etnografia no desvelamento de formas de vida e de pensar diferentes das nossas.

A etnografia tem se mostrado fundamental para a compreensão dos aspectos simbólicos da vida social, na medida em que se baseia na ideia de que os comportamentos humanos só podem ser suficientemente compreendidos dentro do contexto sociocultural no qual eles estão inseridos.

Nessa linha, torna-se fundamental apreendermos o "ponto de vista dos nativos", isto é, o ponto de vista dos sujeitos da pesquisa, a partir da compreensão dos significados que determinadas práticas sociais têm para aqueles que as vivenciam. Significados, esses, que dão sentido à realidade e por meio dos quais os atos cotidianos, os eventos, os fatos, as ações e, inclusive a própria saúde e a doença, tornam-se inteligíveis para aqueles que os vivenciam e sem os quais não existem como categoria cultural.

Nesse contexto, o trabalho de campo, com a realização de observações in loco sobre os comportamentos vivenciados no território da pesquisa, é fundamental permitindo a construção de um conhecimento baseado no confronto entre nossas hipóteses e nossas observações (VICTORA; KNAUTH; HANSEN, 2000).

Todavia, com a pandemia muitos pesquisadores tiveram que adaptar suas pesquisas aos espaços virtuais. Nessa linha, muitas pesquisas etnográficas passaram a ser realizada via internet, incorporando-se à chamada etnografia virtual, etnografia on-line ou mesmo netnografia (HINE, 2004).

Dada a especificidade do fazer etnográfico e seu compromisso com o trabalho de campo, essa adaptação para etnografia virtual não é isenta de implicações teóricas e metodológicas. Como bem aponta Hine (2004), um dos principais problemas enfrentados em estudos etnográficos na internet é encontrar uma forma de interação com os sujeitos do estudo adequada ao propósito etnográfico que a pesquisa requer. Uma vez que, na tradição antropológica, a etnografia demanda a participação do etnógrafo, abertamente ou de maneira discreta em campo, na vida cotidiana das pessoas durante um período de tempo, observando o que acontece, escutando o que se diz e fazendo perguntas. 
Mas, a pesquisa de campo virtual pode ser chamada de etnografia? A etnografia virtual é ainda uma pesquisa etnográfica no sentido antropológico?

Para Hine (2004), a etnografia virtual problematiza essa ideia tradicional da antropologia de trabalho de campo, na medida em que a pesquisa de campo não implica, necessariamente, mover-se de um lugar para outro, ou seja, não requer uma observação participante face a face. Em outras palavras, as possibilidades de interações mediadas pela virtualidade nos permitem repensar essa regra da presença física como um fundamento da etnografia virtual, de modo que, para o pesquisador ter a internet como campo de pesquisa tem como propósito fundamental se aproximar da experiência dos sujeitos e explorar as relações sociais estabelecidas nos espaços virtuais.

\begin{abstract}
Um etnógrafo pode prestar atenção simétrica a ambos os aspectos da Internet cotidiana, buscando explorar as consequências do silêncio da Internet como um componente da vida cotidiana e entender como e quando a identificamos como um grande fenômeno com significantes consequências em grande escala. Um corolário de adotar a "perspectiva do estranho" acalentada na etnografia é procurar explorar como as posições fazem sentido sem dar por certo que o fazem. Tanto a notável como a despercebida Internet cotidiana são, portanto, de interesse etnográfico e passíveis de exploração etnográfica (HINE; PEREIRA; LINS, 2021, p. 35).
\end{abstract}

A etnografia virtual também nos leva a refletir sobre os limites do chamado método etnográfico. Como bem aponta Peirano (2014), a etnografia é sempre reinventada e recriada em cada fazer etnográfico. Somos inventores e inovadores da pesquisa etnográfica. Com efeito, a etnográfica não limita a um método de pesquisa, mas sim, a uma inovação teórica, fruto de uma recombinação intelectual a partir dos objetivos da pesquisa.

Ora, a etnografia virtual faz parte de uma inovação fruto tanto das mediações tecnológicas que cada vez mais fazem parte de nosso dia a dia como também das necessidades impostas pela pandemia, que obrigou os pesquisadores a voltarem seus interesses de pesquisa para o espaço virtual:

\begin{abstract}
A etnografia virtual é, portanto, um método, uma ferramenta que pode ser muito útil para o antropólogo ao analisar textos online, imagens, sons entre outros dados e fenômenos do ciberespaço. Mas para tal, o método deve ser utilizado pelo pesquisador com certos cuidados, pois ele precisa adaptar-se a essa ferramenta, realizando uma análise mais crítica (PEREIRA; MENDES, 2020, p. 210).
\end{abstract}

O etnógrafo virtual realizará um engajamento on-line diferente para cada população com que vier a trabalhar. Nessa linha, como existem muitos contextos para pesquisas presenciais, também existe uma diversidade de contextos on-line e cada um exige uma inovação teórica e metodológica. É o campo que vai informar e formar a 
pesquisa etnográfica. Se agora o campo é virtual é nele que o pesquisador encontrará as condições de possibilidade para realizar a pesquisa etnográfica:

O método é algo que você aprende, não é algo que já começa com você. Argumento que exatamente o mesmo se aplica on-line (...) porque se você estará trabalhando principalmente on-line, é necessário se concentrar ainda mais na observação participante, em vez de coisas como entrevistas. Por quê? Porque, como você deve perceber, há muitas oportunidades para a observação que agora não serão possíveis. Diante disso, o que você precisa fazer nessa espécie de mudança para um novo regime é encontrar maneiras de compensar esse problema, ao prever um modo como fará seu trabalho de campo (MILLER, 2020, p. 4).

Nessa linha, a interação entre pesquisador e sujeitos da pesquisa na etnografia virtual pode acontecer tanto no contexto on-line como off-line, a depender dos objetivos e da especificidade do campo da pesquisa. Alías, a internet reconfigura a noção de campo, que baliza a experiência etnográfica:

A noção de um campo contido na Internet certamente oferece uma lente poderosa para descobrir o que as pessoas fazem online e, em particular, para entender como os espaços online emergem como cenários sociais ordenados. É o caminho para entender um conjunto específico de questões teoricamente orientadas. A etnografia em espaços online pode olhar em detalhes para como uma cultura distinta pode emergir em tal espaço, com seu próprio conjunto de normas e valores, com entendimentos comuns de humor, reciprocidade e um sentido de sua própria identidade como Formação social distinta de outras. Espaços online podem formar entidades sociais coesas que são prontamente descritíveis por termos como comunidade, ou eles podem oferecer formações sociais mais difusas que ainda assim oferecem a seus participantes um senso de que eles estão em um espaço distinto que carrega certas expectativas de seus comportamentos e ainda possuem características receptivas à exploração etnográfica (HINE; PARREIRAS; LINS, 2021, p. 17).

Com isso, a natureza da observação realizada no trabalho etnográfico também tem que ser repensada:

As mídias digitais fornecem um oceano de dados para o etnógrafo realizar o trabalho de campo. Portanto, ao realizar a observação participante no meio virtual, a natureza da observação muda. E também as formas de construir um caderno de campo passam a ser mais tecnológicas, registrando eventos, interações e locais digitalmente. Assim, as observações participantes virtuais incluem interações em salas de bate papo, e-mails, mensagens, sites, entre outros. Contudo, esse tipo de observação consiste em observar textos e imagens por meio da tela do computador por meio da participação ativa em determinado grupo pesquisado, e na oportunidade de observar os grupos online, além de postar e participar nos mesmos (PEREIRA; MENDES, 2020, p. 209).

Ainda segundo Hine (2004), a inserção do pesquisador no campo virtual pode se dar de duas formas, a depender das características do campo: "lurker" ou "insider". A primeira, diz respeito a uma observação participante mais "silenciosa", sem interferência ou interação com o meio investigado. Dito de outra forma, nesse tipo de observação o pesquisador observa, mas não intervém no campo empírico. A segunda é mais relacional, 
"ativa", na qual há uma proximidade e interação significativa entre o pesquisador e os sujeitos da pesquisa (HINE, 2004; PEREIRA NETO et al., 2015).

Os principais problemas metodológicos da inserção do pesquisador correspondem ao informante conduzir a pesquisa de maneira confusa ou não relatar experiências reais, tendo em vista que as entrevistas e relatos precisam ser feitos com bastante atenção por parte do pesquisador, que deve manter um olhar crítico e afastado do objeto, com rigor ao sistematizar os dados coletados e descrições. Isso demanda atenção redobrada, pois publicar determinados relatos e experiências pode afetar a relação do pesquisador e informante. Além disso, o pesquisador lurker precisa entrar no grupo de alguma forma, sendo percebida sua presença em alguns momentos pelos interlocutores (PEREIRA, MENDES, 2020, p. 206).

Para contemplar a complexidade oferecida por essas formas de interação, Hine (2004) sinaliza que para qualquer projeto etnográfico virtual é necessário considerar os fundamentos da sua metodologia. Para isso, a autora reitera os 10 princípios que fundamentam as etnografias virtuais, bem como suas características:

1) A presença continuada do etnógrafo no seu campo de pesquisa, combinado com um profundo compromisso com a vida cotidiana dos sujeitos que ali interagem virtualmente;

2) As mídias interativas nos desafiam e nos dão a oportunidade de fazer etnografia, pois esses espaços se configuram também como espaços de interação social;

3) $\mathrm{O}$ crescimento das interações virtuais nos convida a reconsiderar a ideia de uma etnografia ligada a um espaço concreto, expandindo o conceito inclusive para múltiplos espaços;

4) É necessário repensar o conceito de campo de estudo. O objeto da investigação etnográfica pode ser remodelado ao nos concentrarmos sobre o fluxo e a conectividade em vez da localização e fronteira como princípio de organização;

5) O desafio de etnografia virtual é examinar como estão definidos os limites e conexões, especialmente entre o que é "virtual" e "real";

6) Junto ao deslocamento do conceito espacial, vem o temporal. A etnografia virtual é um interstício, no sentido de que convivem várias atividades tanto do investigador quanto dos participantes do estudo em um dado momento;

7) A etnografia virtual é irremediavelmente parcial. As descrições que surgem do campo podem se basear em ideias de relevância estratégica para a análise e não em representações fiéis a realidade objetiva apresentada;

8) Envolve uma intensa imersão pessoal no campo, para exploração e compreensão das experiências e seus contextos envolvidos; 
9) As novas tecnologias de interação permitem que os informantes apareçam, ou seja, estejam presentes dentro da etnografia e ao mesmo, estejam ausentes;

10) A etnografia não é apenas virtual, no sentido de falta de corpo físico.

A etnografia virtual já é feita por pesquisadores brasileiros que estudam as relações socioculturais na internet. Exemplo disso é o trabalho de Pereira Neto e colaboradores (2015) realizaram uma etnografia virtual em três grupos on-line no Facebook que reúnem pessoas que vivem com diabetes, com hepatite $\mathrm{C}$ e com HIV/aids, onde analisaram o empoderamento proporcionado pela internet e a validade dos saberes médicos na visão desses usuários diante das suas condições. Ou ainda, o trabalho de Separavich e Canesqui (2012), que analisaram as representações e os relatos da experiência com a menopausa contidos no site brasileiro da internet, "Menopausa - o site da mulher madura". Para os autores, tratava-se de um espaço de interatividade, no qual procuraram identificar aspectos do climatério/menopausa, da vivência desse processo e das ações de cuidados adotadas por mulheres que passavam por essa fase da vida. $\mathrm{O}$ trabalho de Melo (2020), no qual estuda grupos de internet de pessoas que vivem com o HIV/aids (PVHA), apontando o modo como a interação em espaços virtuais é fundamental para a superação dos preconceitos e para a construção identitária dos membros do grupo virtual. Lemos (2020) reflete em seu trabalho sobre guerrilhas digitais os processos de poder em torno da formatação dos dados digitais e das próprias Tecnologias de Informação e Comunicação (ICTs), abordando questões como os mecanismos de exclusão. Além disso, ao pensar sobre as infraestruturas do digital, traz importantes reflexões sobre as formas de resistência e de produção de contranarrativas por meio das "guerrilhas digitais" e dos "hackeamentos". Ou exemplo é o trabalho de Santos (2020) que aborda as implicações éticas e metodológicas de uma pesquisa feita no aplicativo Tinder, de encontros afetivos-sexuais, na medida em que ela estava sujeita aos “matches", estabelecendo uma linha tênue entre a relação entre pesquisador e pesquisado. Em estudo com os grupos de ajuda de A.A. na internet, Campos (2021) aborda, em estudo sobre etnografia virtual em Alcoólicos Anônimos, o modo como a pandemia obrigou a mudança das reuniões de recuperação para o meio virtual, o que impactou a realização da pesquisa etnográfica sobre o alcoolismo e suas formas de tratamento.

Esses estudos evidenciam que a etnografia virtual pode e deve ser conduzida pelo pesquisador de maneira ética e como uma oportunidade de compreensão dessa nova maneira de se relacionar e de se vivenciar as experiências nesse contexto de isolamento social imposto pela pandemia. 


\section{A etnografia virtual em grupos de Alcoólicos Anônimos em tempos de pandemia}

Para dar conta dos objetivos propostos foi realizada uma etnografia virtual, com observação participante, em reuniões de recuperação on line de grupos de A.A., localizados na Cidade de São Paulo - Brasil e também entrevistas, por meio de formulário Google Forms, com membros de A.A. de diversas cidades brasileiras. Essa pesquisa foi aprovada pelo Comitê de Ética em Pesquisa, da Escola de Artes, Ciências e Humanidades, da Universidade de São Paulo (CEP-EACH/USP).

O A.A. é, de acordo com sua literatura oficial, "uma irmandade de homens e mulheres que compartilham suas experiências, forças e esperanças, a fim de resolver seu problema comum e ajudar outros a se recuperarem do alcoolismo" (ALCOÓLICOS ANÔNIMOS, 1996).

Um dos aspectos fundamentais do modelo terapêutico da irmandade é a participação dos membros de A.A. em reuniões periódicas, cujo objetivo é também ajudálos a evitar o "primeiro gole" e, assim, a manter a sobriedade. As reuniões podem ocorrer em salas alugadas ou cedidas por igrejas, escolas, instituições correcionais ou de tratamento. As chamadas "reuniões de recuperação" podem ser de dois tipos: "fechadas", compostas apenas por aqueles que se consideram "doentes alcoólicos"; e "abertas", destinadas a todos aqueles que desejam conhecer a irmandade.

Além das reuniões específicas para recuperação, existem outras atividades que são organizadas respeitando-se a autonomia dos grupos. Assim, cada um deles funciona como uma "célula" que possui autonomia para organizar as atividades e reuniões que julgar necessárias, desde que não afete a organização de outros grupos ou da irmandade em seu conjunto. De modo geral, os tipos de reuniões organizadas são os seguintes: Reuniões de Unidade (abertas ou fechadas): são de fato reuniões de recuperação, nas quais dois diferentes grupos, de diferentes bairros ou cidades fazem uma reunião conjunta com membros desses grupos; Reuniões de literatura (abertas ou fechadas): dedicadas à discussão da literatura de Alcoólicos Anônimos; Reuniões temáticas (abertas), nas quais um membro ou um "profissional" convidado disserta sobre um tema de interesse e Reuniões de serviços (fechadas), que são dedicadas à organização administrativa do grupo e utilizadas para a eleição dos servidores responsáveis pelas tarefas de manutenção do grupo.

Com a pandemia, muitos grupos de A.A. suspenderam as reuniões de recuperação presenciais, bem como demais atividades que pudessem causar aglomeração de pessoas 
e, consequentemente, a contaminação pelo Coronavírus. Dessa forma, as reuniões passaram a ser virtuais, de modo que se utilizando da internet, os membros de A.A. pudessem dar continuidade ao tratamento do alcoolismo.

A utilização das mídias sociais não é uma novidade para o A.A., que usa da internet para divulgar suas informações e também para promover troca de experiências entre seus membros, tanto por meio da página na internet da Junta de Serviços Gerais de Alcoólicos Anônimos no Brasil (JUNAAB) ${ }^{2}$, como de um grupo privado no Facebook, cujo nome é: Alcoólicos Anônimos Brasil (AA). O que passou a ser novo com a pandemia é centralidade que as reuniões virtuais passaram a ocupar no tratamento do alcoolismo. Com a impossibilidade de se fazer reuniões presenciais, alguns grupos de A.A. passaram a promover reuniões on-line, o que exigiu uma adaptação de seus membros a essa nova realidade imposta pela pandemia.

Se a pandemia exigiu essa reorganização de A.A., o mesmo aconteceu na pesquisa etnográfica, que também teve que ser feita na forma virtual. Na página da internet da JUNAAB é possível saber quais grupos de A.A., no Brasil, realizam reuniões à distância ${ }^{3}$. A Cidade de São Paulo conta com 121 grupos de A.A, mas, apenas 19 grupos promovem reuniões de recuperação on-line abertas, com média de uma hora e meia de duração e cujo acesso se dá tanto pela plataforma Google Meet, como pelo Zoom ${ }^{4}$. Há também reuniões virtuais fechadas somente para membros de A.A.. ${ }^{5}$

$\mathrm{Na}$ página de A.A. também se encontra orientações sobre o modo como deve transcorrer o acesso e a dinâmica das reuniões. Com efeito, é proibida a gravação das reuniões e todos devem manter a câmera de vídeo desligada em respeito ao princípio do anonimato ${ }^{6}$. Há também ressalvas quanto aos cuidados para se evitar interrupções das reuniões, em relação às movimentações na casa dos participantes e quanto à vestimenta.

Mas, como são as reuniões de recuperação virtuais? Quais as diferenças entre as reuniões virtuais e presenciais? Foi munido dessas questões que eu entrei na página da internet de A.A. e vi os dias e horários das reuniões de recuperação virtuais e iniciei a

\footnotetext{
${ }^{2}$ Cf. https://www.aa.org.br/ (Acesso em 02. jul. 2021).

${ }^{3} \mathrm{Cf}$. https://sites.google.com/aa.org.br/g-suite/reunioes-a-distancia/lista-das-reunioes (Acesso em 02. jul. 2021).

${ }^{4}$ Cf.https://sites.google.com/aa.org.br/g-suite/reunioes-a-distancia/lista-das-reunioes/saopaulo\#h.njhz8cxlq6j3 (Acesso em 02 jul. 2021).

${ }^{5} \mathrm{Cf}$. https://sites.google.com/aa.org.br/g-suite/reunioes-a-distancia/reunioes-para-membros (Acesso em 02 jul. 2021).

${ }^{6}$ A Décima Segunda tradição de A.A. aponta: "O anonimato é o alicerce espiritual de todas as nossas tradições, lembrando-nos sempre da necessidade de colocar os princípios acima das personalidades" (ALCOÓLICOS ANÔNIMOS, 1996).
} 
pesquisa de campo, em dois grupos virtuais de A.A., aqui denominados Grupo 1 e Grupo 2, com reuniões todos os dias da semana das $19 \mathrm{~h} 00$ às $20 \mathrm{~h} 30$, pela plataforma Google Meet e Zoom.

No início da reunião, o coordenador lê um preâmbulo, com a reflexão diária, extraída dos escritos de Bill Wilson (ALCOÓLICOS ANÔNIMOS, 2000), fundador do A.A., e chama a todos para fazerem a Oração da Serenidade ${ }^{7}$. O coordenador chama a atenção dos membros sobre os cuidados que devem ser tomados em relação ao anonimato. Após, dá-se início as partilhas com cada participante tem 10 minutos para compartilhar suas experiências tanto do tempo do alcoolismo ativo, como do tempo de recuperação em A.A.. A partir daí, o coordenador convida os membros de A.A. a fazer a partilha, que é ouvida por todos em silêncio: "Meu nome é Roberto, sou um doente alcoólico em recuperação e participo da reunião para não ter consciência do meu alcoolismo, que preciso de ajuda e agradeço ao Poder Superior e aos Alcoólicos Anônimos por eu não voltar a beber. Eu tenho um problema com minha ex-mulher, mas sei que pelo meu alcoolismo, eu não posso perder a cabeça”. (Roberto, reunião de recuperação virtual, Grupo 1). "Meu nome é Cris e sou doente alcoólico em recuperação. Participo das reuniões virtuais, mas sinto falta do grupo, tenho saudade, eu preciso sentir a unidade presencialmente”. (Cris, reunião de recuperação virtual, Grupo 2). "Meu nome é Fátima, uma alcoólica em recuperação. Hoje, eu estou triste porque não tenho filhos, mas eu cuidei de um sobrinho que me considera como sua mãe, mas, a namorada de meu irmão não cuida dele". (Fátima, reunião de recuperação virtual, Grupo 1). "Meu nome é Elisa, sou alcoólatra em recuperação e agradeço ao Poder Superior por eu não voltar a beber. Sou filha de pai alcoólatra e comecei a beber em casa. Depois comecei a beber socialmente, e minhas amigas me diziam de meu comportamento quando eu bebia; que eu perdia o controle, muito vexatório. Eu ofendia meus amigos, minha mãe, até que eu resolvi procurar o A.A..” (Elisa, reunião de recuperação virtual, Grupo 2). Ao longo da reunião, o coordenador lê mensagens de incentivo para que os membros continuem sua recuperação. Após uma hora de reunião, o coordenador lê a sétima tradição, que diz sobre as contribuições financeiras voluntárias para manter o funcionamento do grupo e também passa informações sobre as atividades promovidas pelo grupo. Ao final, da reunião o coordenador faz o encerramento da reunião, convidada a todos a fazer novamente a

\footnotetext{
${ }^{7}$ A Oração da Serenidade é feita no início e no final das reuniões de recuperação, virtuais e presenciais: "Concedei-nos Senhor, a serenidade necessária para aceitas as coisas que não podemos modificar. Coragem, para modificar aquelas que podemos. E, Sabedoria, para discernir uma das outras”.
} 
Oração da Serenidade. Todos se despedem, com votos de boa noite e o link da reunião virtual é encerrado.

Além da observação participante em reuniões de recuperação virtuais, também foram realizadas entrevistas, via formulário Google Forms, com 35 membros de A.A. de diferentes cidades brasileiras. O formulário possuía um registro de consentimento, no qual se explicava os objetivos da pesquisa, a garantia do anonimato e o direito de não participar da pesquisa e o consentimento para divulgação dos dados obtidos na entrevista. Além disso, o formulário possuía o registro de dados pessoais, tais como: nome, idade, estado civil, naturalidade, escolaridade, profissão, tempo de A.A. e grupo base. Os participantes eram convidados a responder a seguinte pergunta: "A pandemia afetou o tratamento do alcoolismo em A.A.? Se sim, como?".

Dentre os entrevistados, tem-se que 19 são do Estado de São Paulo - Capital, 10 são do Estado de São Paulo, de cidades do interior e litoral, 04 são do Estado da Bahia, 01 é do Estado do Rio de Janeiro e 01 do Distrito Federal. Os entrevistados têm idade entre 35 e 69 anos e a maioria é casada, alguns com companheiras e companheiros de A.A.. O tempo de A.A varia entre 02 meses a 30 anos.

As entrevistas, através do Google forms, foram fundamentais para a pesquisa, pois permitiram uma aproximação mais intensa com os membros de A.A. em tempos de pandemia. Com efeito, se, nas reuniões virtuais, foi possível observar a maneira como ocorre a recuperação, nas entrevistas é possível estabelecer um maior controle sobre os dados, de maneira a compreender a maneira como os membros de A.A. avaliam os efeitos da pandemia para o tratamento do alcoolismo.

\section{Alcoólicos Anônimos e a pandemia: os desafios da etnografia virtual}

A análise dos dados visa compreender tanto os efeitos da pandemia no tratamento do alcoolismo em A.A. como os desafios da etnografia virtual, particularmente, em relação à entrada no campo de pesquisa, à interação entre pesquisador e pesquisado, à utilização das técnicas de pesquisa, observação participante e à análise dos dados obtidos.

Todos os entrevistados sinalizaram que a pandemia afetou o tratamento do alcoolismo em A.A., obrigando os grupos a se adaptarem a essa nova situação. É o que vemos, por exemplo, na resposta a seguir: "Quando as primeiras quarentenas foram decretadas, no mundo inteiro, aliás, acredito que todos nós sofremos um impacto violento (...) Mas logo começamos a "abrir picada" começando pela boa e velha terapia do 
telefone, do Whatsapp e das videoconferências. Inúmeros grupos passaram a abrir reuniões em meio virtual e logo a JUNAAB passou a disponibilizar esse canal para nossas áreas (conjuntos de distritos) e distritos (conjuntos de grupos), de modo que, de março de 2020 até agora, centenas delas passaram a ser oferecidas.” (Elaine, 60 anos, casada, São Paulo-Capital, 28 anos de A.A.). Os membros de A.A. entrevistados também reconhecem que tiveram que se adaptar aos novos tempos para dar continuidade à recuperação: "A frequência às reuniões é a base da recuperação principalmente para membros novos/as. Mas, entendo que a grande sacada do AA, a chave de ouro, é o programa dos 12 passos. Adaptar-se as mudanças. Para os membros/as mais conservadores/as foi e creio que ainda está sendo um pouco traumático." (Max, 43 anos, solteiro, Rio de Janeiro, 5 anos de A.A.). Ou ainda, "a pandemia ajudou, pois, as plataformas nos favoreceram no acesso a inúmeras reuniões de literatura e temática, que aprendemos muito e estamos em constante aprendizado" (Luiza, 48 anos, casada, Distrito federal, um ano e 06 meses de A.A.).

Mas, a pandemia também criou dificuldades de acesso, pois, nem todos conseguem participar das reuniões virtuais: "a falta de reuniões presencias é um problema real. Eu tenho a condição de ter internet e bom celular computador e estar fazendo minha recuperação online. Como nas escolas, as reuniões à distância não atingem a todos" (Lidiane, 61 anos, divorciada, Bahia, 19 anos de A.A.). A pandemia também provocou o fechamento de grupos favorecendo as recaídas: "a pandemia afetou sim como afetou todo segmento da nossa sociedade o fechamento de muitos grupos e muitos companheiros recaíram" (Rosalia, 63 anos, viúva, São Paulo-Capital, 05 anos de A.A.). "Infelizmente sim, com o fechamento de muitas salas ficamos sem nosso remédio diário que são as reuniões. E os membros mais novos acabaram ficando mais vulneráveis". (Rossana, 49 anos, casada, Limeira, 02 anos de A.A.).

Um aspecto importante ressaltado nas entrevistas foi a possibilidade de atrair novos membros, ou de "levar a mensagem de A.A." para aqueles que precisam de ajuda: "as reuniões em meio virtual começaram a se tornar "portas de entrada" capazes de atrair jovens e mulheres como nunca antes na história de A.A. Como também pessoas que vivem em regiões onde não existem grupos locais de A.A.." (Elaine, 60 anos, casada, São Paulo-Capital, 28 anos de A.A.).

Se as entrevistas revelaram as dificuldades enfrentadas pelos membros de A.A. para realizarem o tratamento do alcoolismo em tempos de pandemia, a observação participante nas reuniões de recuperação virtuais mostrou o modo como a troca de experiências, mesmo online, é fundamental para a consolidação tanto da noção do alcoolismo 
concebido como "doença fatal" como da identidade do "doente alcoólico". Em estudo anterior (CAMPOS, 2010), mostramos como o A.A. opera como um modelo terapêutico no qual se constrói os significados da experiência do alcoolismo como doença e de seus membros como doentes alcoólicos em recuperação. Ao longo das partilhas, os membros de A.A. vão tecendo suas experiências vividas, na vida familiar e no trabalho, entrelaçando-as com a doença do alcoolismo. Com efeito, a etnografia virtual, com a observação das reuniões online, permite compreender o modelo terapêutico de A.A. em ato, ou seja, no momento em que seus membros se reúnem virtualmente e compartilham suas experiências para se recuperarem do alcoolismo e se reconhecerem como doentes nessa pandemia.

A análise dos dados coletados na etnografia virtual aponta que para a reafirmação da condição de doente alcoólico, que necessita das reuniões virtuais como um ambiente que permite as trocas de experiências e, por essa via, o tratamento do alcoolismo, concebido como uma doença fatal, em tempos de pandemia.

A pandemia afetou o método de pesquisa e as técnicas para coleta de dados, impondo desafios ao pesquisador. Com efeito, um desafio fundamental é a entrada no campo de pesquisa, que exige uma preparação prévia, com contato com o coordenador das reuniões ou com membros de A.A. ativos. Esse contato prévio é importante para a entrada no campo, o que não diminuiu a curiosidade e o estranhamento provocado pela presença de um pesquisador "não alcoólico" na reunião. Em estudo anterior, apontamos a importância de se responder às questões feitas pelos membros de A.A. e de se deixar claro os objetivos da pesquisa (CAMPOS, 2017).

Um aspecto fundamental da etnografia virtual diz respeito ao anonimato, que, como vimos, é um princípio fundamental das Tradições de A.A.. Assim, nas reuniões online o anonimato virtual, proporcionado pela internet, na qual o participante da reunião pode não abrir a câmera, ou mesmo, ter um pseudônimo como identificação, garante uma espécie de "proteção", uma vez que o risco de preconceito, discriminação e rejeição é reduzido por ter a identidade protegida pelo anonimato.

Uma vez na sala de reunião virtual de A.A., o pesquisador deve manter uma discrição e fazer a observação participante, com anotações detalhadas em diário de campo de toda a dinâmica da reunião. Embora se exija a discrição, o pesquisador pode reproduzir certas práticas realizadas durante as reuniões (FAINZANG, 2002), como, por exemplo, fazer a oração da serenidade, ao início e término das reuniões. Desse modo, o pesquisador coloca em prática certos códigos ritualizados, que assinalam seu envolvimento com o 
grupo. Com isso, sua posição dentro do grupo virtual vai se consolidando cada vez mais, de maneira a facilitar o acesso às informações necessárias para o trabalho de campo, delimitando seu "lugar" entre os membros de A.A..

É fundamental que o pesquisador participe com regularidade das reuniões, para que possa colher as informações essenciais de acordo com os objetivos da pesquisa. Durante a reunião virtual, é importante observar o modo como ocorrem as partilhas, a entonação da voz, as emoções, os sentimentos, são elementos extremamente significativos para a etnografia. É importante também observar se algum dos participantes da reunião abre a câmera, de modo a revelar sua identidade, mesmo com a recomendação para não fazê-lo. Uma atenção também é importante para os silêncios, sobretudo, daqueles que não se sentem a vontade de fazerem a partilha no meio virtual, anotando-se no diário de campo, quantos membros fizeram a partilha e quantos não quiseram fazê-la.

A depender da disponibilidade, os participantes da reunião poderão ser convidados para entrevistas individuais que ser on-line por meio de chats, e-mails ou sessões no Skype. Em tais situações, o pesquisador deverá solicitar autorização prévia para uso do registro da "conversa escrita" ou gravação da voz ou imagem se assim permitir o interlocutor, obedecendo aos direitos de privacidade dos entrevistados.

Em se tratando dos riscos decorrentes da pesquisa para os entrevistados, algumas estratégias de enfrentamento devem ser utilizadas pelo pesquisador, como por exemplo, diante do constrangimento no momento de responder a alguma pergunta do roteiro de entrevista, informar ao entrevistado que ele terá a possibilidade de se retirar da pesquisa em qualquer fase da coleta de dados sem nenhum prejuízo.

Nessa linha, o pesquisador precisa ter o compromisso ético com seus pesquisados. Como afirmam Pereira, Mendes (2020, p. 210): “o pesquisador precisa ainda atentar à ética, havendo uma preocupação com a intimidade e privacidade dos sujeitos, que precisam estar sempre em primeiro lugar em uma pesquisa de campo que envolve interlocutores".

Nessa linha, com o objetivo de garantir a consideração de todos os interesses envolvidos no trabalho e coleta de dados, cada entrevistado deve tomar conhecimento do Registro de Consentimento, tal como previsto na Resolução 510, Conselho Nacional de Saúde (BRASIL, 2016), no qual autorizará sua participação, bem como a utilização dos dados obtidos em resposta em futuras publicações.

A questão do consentimento em participar de pesquisa no ambiente digital é um ponto essencial para a realização da etnografia virtual. Esse questionamento foi colocado 
por Monaco (2020), em seu estudo sobre grupos de mulheres ficisulturistas na rede social Facebook. Vale, portanto, retomar suas indagações sobre os dilemas relacionados ao consentimento

p-0em participar de uma pesquisa feita na internet:

Quem tem o direito de consentir ou recusar a participação na pesquisa antropológica? E, ainda, a quem pertencem os espaços digitais - aos criadores (sejam eles as empresas como o Facebook ou os administradores de grupos e páginas) ou às pessoas que vivenciam e constroem cotidianamente aqueles espaços? (MONACO, 2020, p. 14).

A realização de um trabalho de campo não depende apenas do pesquisador, mas é construído e delimitado na interação do pesquisador com os participantes da pesquisa. Nesse sentido, as definições desses limites têm que ser estabelecidas contextualmente, uma vez que os grupos estudados não são homogêneos.

Não há resposta pronta e universal a essas questões, mas, no caso aqui abordado, a solução adotada foi construir a pesquisa em conjunto com os sujeitos, aqueles que quiseram construir, dentro dos limites que as negociações permitiram. Daí a importância de negociar com os sujeitos da pesquisa, reconhecendo-os como entidades políticas dotadas de critérios de avaliação ética. Nas palavras da autora:

\begin{abstract}
Importa lembrar que a relação entre pesquisadora e pesquisados na pesquisa etnográfica é desigual e assimétrica, uma vez que, como pesquisadora e sobretudo como autora, eu já terei a palavra final, no texto. Por isso, é imprescindível garantir que os sujeitos da pesquisa tenham algum dizer sobre a narrativa que será escrita sobre eles, afinal, são narrativas sobre suas vidas (MONACO, 2020, p. 15).
\end{abstract}

A antropologia engloba e domestica os usos que outras pessoas fazem de suas vidas, o que, por vezes, pode ser vivenciado como uma exploração. Isso porque as pessoas pesquisadas percebem que esse englobamento significa uma transformação dos dados em materiais cujo valor não pode ser restituído a elas. É necessário reconhecer que os participantes de uma pesquisa são capazes de avaliação ética e têm o direito sobre as informações prestadas durante o trabalho de campo.

Ainda segundo a autora:

Não obstante, importa lembrar que o trabalho de campo não tem fronteiras definidas entre vida e pesquisa. Ele está por toda parte e a observação participante é caracterizada por sua informalidade. Nesse sentido, estamos sempre observando e a vida faz parte da pesquisa. Por sua vez, as mídias digitais são parte importante da vida cotidiana de grande parte das pessoas, inclusive pesquisadoras. Como antropóloga, não há como separar estritamente o que eu vejo, ouço e faço nos ambientes digitais por onde circulo e os dados de pesquisa construídos na relação com os sujeitos (MONACO, 2020, p. 16). 
Essas reflexões são fundamentais, na medida em que indicam a exigência do compromisso ético do pesquisador na realização da pesquisa etnográfica, particularmente, no contexto da pandemia, no qual os participantes que estão vulneráveis, são convertidos em objeto de estudo da pesquisa científica.

\section{Considereções finais}

Este artigo buscou compreender a maneira como os membros A.A. se adaptaram a essa nova realidade imposta pela pandemia para realizarem o tratamento do alcoolismo, bem como os desafios da etnografia virtual.

Com efeito, foi realizada observação participante em reuniões virtuais de A.A., nas quais os membros do grupo podem compartilhar suas experiências dos tempos do alcoolismo ativo e também da pandemia, reafirmando sua condição de doentes alcoólicos em recuperação. Já as entrevistas com membros de A.A. apontaram os efeitos da pandemia para o tratamento do alcoolismo, nas quais, se reconhece as dificuldades para o acesso à reunião virtual, a falta da reunião presencial e do contato direto entre os membros do grupo. Por outro lado, os entrevistados também ressaltam as possibilidades abertas pelas reuniões virtuais, tornando possível atrair novos membros e aumentar o acesso à doutrina de A.A.

Assim, apesar das dificuldades impostas pela pandemia, a etnografia em A.A. revelou-se fundamental, na medida em que permitiu uma análise rica dos significados do alcoolismo, a partir da observação da maneira como os membros da irmandade concebem e vivenciam seu tratamento em contexto virtual. Todavia, mais pesquisas qualitativas são necessárias para se compreender as experiências e os desafios impostos pela pandemia aos membros de A.A. e aos pesquisadores de pesquisa qualitativa que se valem da metodologia da etnografia virtual.

A confiabilidade deste estudo é garantida pelo fato de ser realizado em reuniões virtuais de A.A., nas quais os participantes se reconhecem dependentes do álcool e concordaram em participar da pesquisa e forneceram os dados a partir das experiências vividas.

A etnografia permite ao pesquisador de investigação qualitativa um contato direto com o universo da pesquisa de campo, dentro do contexto onde os sujeitos estão inseridos. A entrevista e a etnografia virtual são instrumentos fundamentais para a compreensão da relação entre o dizer e o fazer, isto é, entre aquilo que os membros de A.A. dizem sobre 
os efeitos da pandemia em sua recuperação e aquilo que eles fazem nas reuniões virtuais para tratarem do alcoolismo.

A etnografia virtual deve ser precedida de uma preparação prévia para entrada no campo de pesquisa, de modo a permitir a coleta de dados para posterior análise. Para isso, o pesquisador deve ter presente os objetivos e os fundamentos teóricos da pesquisa que irão nortear a realização do trabalho do campo.

Com efeito, o ambiente virtual se mostra tanto o contexto possível para a realização da pesquisa etnográfica, exigindo do pesquisador, que realiza pesquisa qualitativa, um compromisso ético para a realização do trabalho de campo, como permite aos membros de A.A. a continuidade do tratamento do alcoolismo, por meio das reuniões de recuperação online, nesses tempos de pandemia.

\section{Agradecimentos}

Agradeço à FAPESP pelo apoio a essa pesquisa, processo número: 2017/18535-9. Agradeço também às alunas: Andressa Gabrielle Teixeira do Valle, Mariana Melo e Marselle Ferreira Salles, que colaboraram na coleta das entrevistas.

\section{Referências}

ALCOÓLICOS ANÔNIMOS. O Grupo de AA: onde tudo começa. São Paulo: JUNAAB Junta de Serviços Gerais de Alcoólicos Anônimos, 1996.

ALCOÓLICOS ANÔNIMOS. Reflexões diárias. 4. ed. São Paulo: JUNAAB - Junta de Serviços Gerais de Alcoólicos Anônimos, 2000.

BRASIL. Resolução n ${ }^{0}$ 510, de 07 de abril de 2016. Dispõe sobre as normas aplicáveis a pesquisas em Ciências Humanas e Sociais. Diário Oficial [da] República Federativa do Brasil, Brasília, DF, 24 maio 2016. Disponível em:

https://bvsms.saude.gov.br/bvs/saudelegis/cns/2016/res0510_07_04_2016.html. Acesso em: 18 abr. 2021.

CAMPOS. E. A. "Nosso remédio é a palavra": uma etnografia sobre o modelo terapêutico de Alcoólicos Anônimos. Rio de Janeiro: Editora FIOCRUZ, 2010.

CAMPOS. E. A. Etnografia na pesquisa em saúde: alcoolismo, doença e significado em um grupo de Alcoólicos Anônimos. In: CONGRESSO IBERO-AMERICANO EM

INVESTIGAÇÃO QUALITATIVA, 6., 2017, Salamanca. Anais... Lisboa: Ludomedia, 2017. p. 537-545.

CAMPOS, E. A. Etnografia virtual em Alcoólicos Anônimos em tempos de pandemia: desafios teóricos e metodológicos. In: CONGRESSO IBERO-AMERICANO EM INVESTIGAÇÃO

QUALITATIVA, 11., 2021, Lisboa. Anais... Lisboa: Ludomédia, 2021. p. 102-109. 
FAINZANG, S. De l'autre côté du miroir: réflexions méthodologiques et épistémologiques sur l'ethnologie des anciens alcooliques. In: GHASARIAN, C. (org.). De l'ethnographie à l'anthropologie réflexive: nouveaux terrains, nouvelles pratiques, nouveaux enjeux. Paris: Armand Colin, 2002. p. 63-71.

HINE, C. Etnografía virtual. Barcelona: Editorial UOC, 2004.

HINE, C.; PARREIRAS, C.; LINS, B. A. A internet 3E: uma internet incorporada, corporificada e cotidiana. Cadernos De Campo, São Paulo, v. 29, n. 2, p. e181370, 2020.

LEMOS, R. L. Guerrilha digital e produção de contranarrativas: resistindo aos impactos dos mecanismos de dominação de memória na internet. Cadernos De Campo, São Paulo. v. 29, n. 2, p. e175020, 2020.

MALINOWISKI, B. Introdução: o assunto, o método e o objetivo desta investigação. In: Eunice Ribeiro Durham (org.). Coleção Grandes Cientistas Sociais. São Paulo: Ática, p. 24-48, 1986.

MELO, L. P. Sofrimento social e ajuda mútua entre pessoas que vivem com HIV/aids em uma rede social na internet. Relatório de Pesquisa. São Paulo: FAPESP, 2020.

MILLER, D. Como conduzir uma etnografia durante o isolamento social. Blog do Sociofilo. Disponível em: https://blogdolabemus.com/2020/05/23/notas-sobre-a-pandemia-comoconduzir-uma-etnografia-durante-o-isolamento-social-por-daniel-miller. Acesso em: 18 abr. 2021.

MONACO, H.M. Quem cala consente? Ambientes digitais e suas implicações para a pesquisa antropológica. Cadernos De Campo, São Paulo, v. 29, n. 2, p. 1-19. p. e175295, 2020.

PEREIRA, S.C.S., MENDES, S.P.C. Um debate sobre o campo online e a etnografia virtual. TECCOGS - Revista Digital de Tecnologias Cognitivas, São Paulo, n. 21, p. 196-212, jan./jun. 2020.

PEIRANO, M. Etnografia não é método. Horizontes Antropológicos, Porto Alegre, v. 20, n.42, p. 377-391, jul./dez. 2014.

PEREIRA NETO, A. P. et al. O paciente informado e os saberes médicos: um estudo de etnografia virtual em comunidades de doentes no Facebook. História, Ciências, SaúdeManguinhos, Rio de Janeiro, v. 22, p. 1653-1671, dez. 2015.

SANTOS, S. C. Imersões, fluxos e desafios em uma etnografia no Tinder. Cadernos De Campo, São Paulo, v. 29, n. 2, p. e175168, 2020.

SEPARAVICH, M.A., CANESQUI, A.M. Análise das narrativas sobre a menopausa de um site brasileiro da internet. Interface: Comunicação, Saúde, Educação, Botucatu, v. 16, n. 42, p. 609622, set. 2012.

VICTORA, C.; KNAUTH, D.; HANSEN, M. Pesquisa qualitativa em Saúde: uma introdução ao tema. Porto Alegre: Tomo Editorial, 2000.

Recebido em: 10 de julho de 2021.

Aceito em: 21 de agosto de 2021. 